\title{
Experimental Verification of Applications Options RFID Technology in Real Conditions
}

\author{
Michal Balog ${ }^{1}$, Monika Trojanová ${ }^{2}$, Peter Balog 3 \\ \{michal.balog@tuke.sk ${ }^{1}$, monika.trojanova@tuke.sk ${ }^{2}$, peter.balog@tuke.sk ${ }^{3}$ \} \\ Technical University of Košice, Department of Industrial Engineering and Informatics, \\ Faculty of Manufacturing Technologies, Bayerova 1, 08001 Prešov, Slovak Republic, 1,2, \\ Technical University of Košice, Institute of Logistics, Faculty of Mining, Ecology, Process \\ Control and Geotechnology, Park Komenského 14, 04001 Košice, Slovak Republic ${ }^{3}$
}

\begin{abstract}
Continuous pressure to inform industry and the entire society requires a wide range of quality and reliable components. A fact must be taken into account that each environment of application is specific and therefore the components and requirements for them are different. For elements of radiofrequency identification - RFID that is also true, therefore a whole range of RFID tags are emerging and are looking for their application in practice. The technical parameters mentioned by the manufacturer are often not true or do not include the parameter that a particular application requires. It is difficult to predict how this component will be deport in the real-world environment of the application, therefore investigation of the components of RFID systems and analyze their behavior in different situations allows to simulate and then design information technologies in real-life conditions.
\end{abstract}

Keywords: RFID - Radiofrequency identification, Informatization, Industry 4.0

\section{Introduction}

The Fourth Industrial Revolution, or Industry 4.0, has a number of distinctive features, depending on how a particular firm or institution decides to proceed. Based on the widely-expanded version, it is the current trend in automation and high-quality information flows in production technologies using cyber-physical environment. Industry 4.0 is characterized by the digitization of the manufacturing sector, typical of the surge in data volume, computing power and connectivity (especially in new low-power networks). High-performance information 
technology provides new alternatives to analytics and business intelligence, unusual collaboration between people and machines, such as touch interfaces and the like. In Fig. 1 is a time axis of Industry 4.0. [1],[2]

Research and development of intelligent products are intense and are capable of actively communicating with their users, for example, reporting their technical status, their position, state of the art, etc.

In 2013, one of the Hanover fairs was that in the interconnected world of Industry 4.0 intelligent factories will be part of the so-called Smart Infrastructure and the Internet of Things Network. Horizontal and vertical process integration can achieve an absolute new level in the broader engagement of smart products, where intelligent manufacturing will enable people, machines and material to interact with each other in a way similar to social networking. Smart products will be able to contribute to improving the quality of the production process, which will then be smoother, more efficient and more reliable. [2]

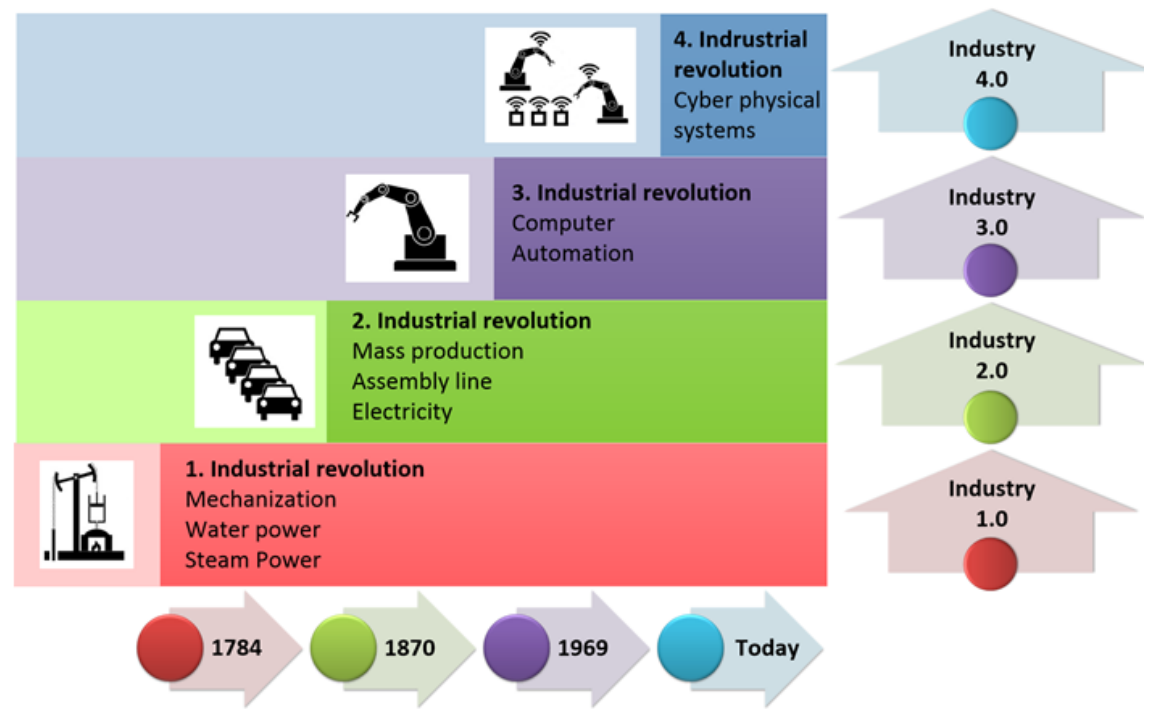

Fig. 1 Time axis of Industry 4.0

A highly intelligent environment will also have to meet all the components of the information systems, which in addition to their ability to work efficiently with enormous amounts of data, will also need to be functional in the full range of associated and necessary environmental influences such as temperature, pressure, humidity, magnetism, vibration and so on. The experiments carried out at the department of industrial engineering and informatics of Faculty of manufacturing technologies with a seat in Prešov, on selected RFID tags have shown that often the declared parameters, at temperature do not correspond to realities and other than vibration, manufacturers do not even mention. Specific applications for the fourth industrial revolution, however, are mining operations, blast furnaces, but also rail transport, where all the parameters mentioned, such as temperature, magnetism, humidity, vibrations exist in negligible values. [3] 


\section{RFID - perspective technology of automatic identification}

Radio-frequency identification is technology of an automatic identification in which the data is stored in a digital form in the so-called RFID tags (chips, labels) from which they can then be loaded and rewritten in a simple way using radio waves. The technology is relatively simple, it has its undisputed advantages over other identification technologies, and it will gradually replace, for example barcodes. The RFID tag is the information carrier which may be in the form of a label or in a closed form of different shapes, sizes and materials. For reading and writing of data to the RFID tags is used RFID reader, which can take various forms (mobile terminal, stationary gate, handheld reader, etc.) A control system that provides bulk processing of read tags within the reader's reach and the transfer of data to a bound information or control system is called middleware. [4],[5]

The basic RFID system (see Fig. 2) consists of RFID tags made of microchips with an antenna and a reader with an antenna. The reading device broadcast electromagnetic waves to which the antenna of the tag is tuned. The antenna serves to exchange the data and transmission energy required for the chip, which is the basis of a system for storing and transferring information. For passive RFID tags, the field thus created is used to power the microchip circuitry, for active RFID tags, energy is obtained from the integrated battery. The microchip then creates waves that send the tag back to the reader that converts them into digital form. [4],[6]

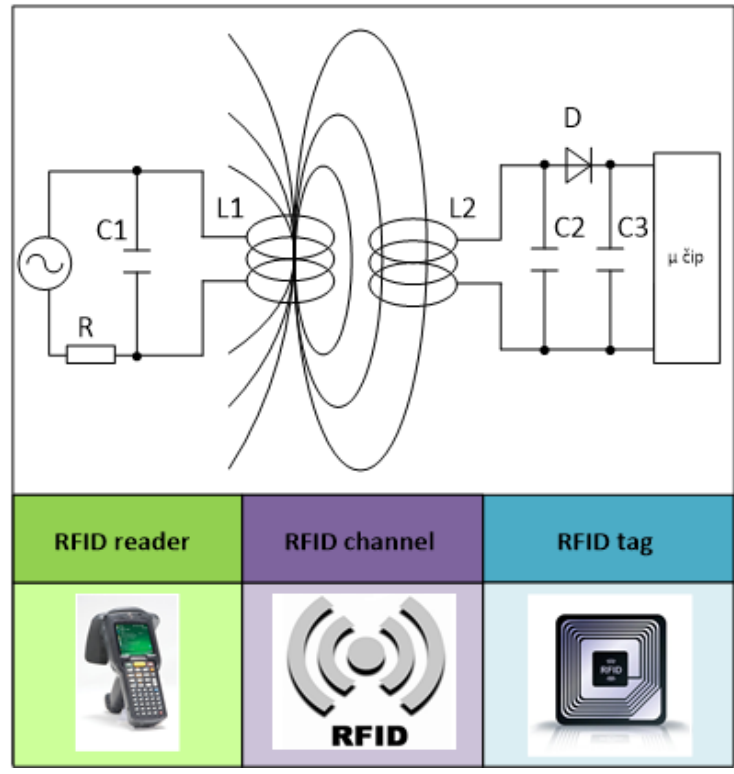

Fig. 2 The principle of RFID activity 
The maximum read distance for transponders depends on several factors [7]:

- tag sensitivity,

- mutual position, orientation and polarization of the antenna and tag,

- the distance between the reader and the tag

- the speed of the tag movement in the read area,

- use of carrier frequency,

- current conditions (noise, more tags next to each other, obstacles).

Radiation characteristics of the RFID antenna and transponder are very important for RFID system designs. The RFID system will not work well and reliably if these characteristics are not sufficiently overlapped. The overlap of characteristics is necessary for the reader to retrieve the tag. Without this tag and antenna overlap, the practical RFID system is inoperative because the antenna does not receive a return signal and the reader evaluates that there is no readable object in the vicinity. The ideal radiation pattern of antenna is shown in Fig. 3, where the individual lobes of the antenna array are shown. [7]

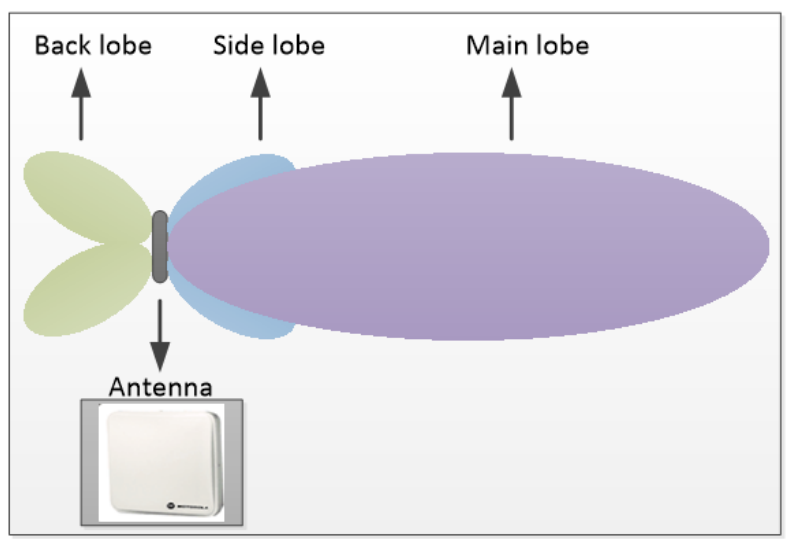

Fig. 3. Ideal radiant characteristic of antenna

The radio frequency of the RFID tag affects its activity (Table 1). Low frequency RFID systems need less energy and its ripple passes better non-metallic materials, however, their working range is relatively small. Higher frequencies increase the energy demands of the broadcast and the cost of the entire system. The advantage is that there is an increase in the working range and also a faster exchange of data between the reader and the tag. By using active tags, it is possible to get a working range of several dozen meters. Thanks to high transmission speeds, the system can be deployed to fast-moving production (eg electronic road toll). With high frequency systems is transfer of data faster and more read-out than with low-frequency systems. The disadvantage is higher power consumption and poor signal throughput through obstructions. Because of this, there is a need for direct visibility between the tag and the reader. [5],[8] 
Table 1. Overview frequency of RFID system

\begin{tabular}{|c|c|c|c|c|}
\hline & \multicolumn{4}{|c|}{ Tag type } \\
\hline & LF tag & HF tag & UHF tag & MW tag \\
\hline Frequency & $\begin{array}{c}\text { Low } \\
125-148 \mathrm{kHz}\end{array}$ & $\begin{array}{c}\text { High } \\
\text { 13-56 MHz }\end{array}$ & $\begin{array}{c}\text { Very high } \\
\text { 860-950 MHz }\end{array}$ & $\begin{array}{c}\text { Microwawe } \\
2,45-5,8 \mathrm{GHz}\end{array}$ \\
\hline Range [m] & $0-0,5$ & $0,5-1$ & $1-3$ & $3-10$ \\
\hline $\begin{array}{l}\text { Scanning } \\
\text { speed }\end{array}$ & Low & Sufficient & High & $\begin{array}{c}\text { Possibility } \\
\text { of extremely } \\
\text { high }\end{array}$ \\
\hline $\begin{array}{l}\text { Production } \\
\text { costs }\end{array}$ & High & High & High & High \\
\hline $\begin{array}{l}\text { Shooting } \\
\text { options }\end{array}$ & $\begin{array}{l}\text { On the metal, } \\
\text { Through the } \\
\text { liquid }\end{array}$ & $\begin{array}{l}\text { Difficult } \\
\text { scanning } \\
\text { through the } \\
\text { liquid }\end{array}$ & $\begin{array}{l}\text { It can not be } \\
\text { scan through } \\
\text { the liquid, } \\
\text { Difficult } \\
\text { scanning on } \\
\text { the metal }\end{array}$ & $\begin{array}{c}\text { The danger of } \\
\text { zero standing } \\
\text { waves }\end{array}$ \\
\hline
\end{tabular}

\section{Laboratory conditions and measurement methodology}

Companies engaged in designing RFID systems for custom looking at everything needed to operate the system from the antenna, reader, software to transponders, but each application to the real world is unique to its distribution and layout of interfering elements that the system does not work on 100\% at some time. According to the chronology after making the design and documentation follows the implementation of the proposed system in practice, where the system must meet all the criteria set by the client, but in the first place the grouping of the elements must be functional and reliable. After a subsequent run, many times it turns out that the system is not working reliably, so that reading RFID tags is not constant or transponders do not load at all. After this finding, in most of these cases the antenna location changes because its range is not sufficient and the RFID transponder is not loaded. In the latter case, additional antennas are added due to insufficient coverage area. In order to incorporate component parameters into simulation models and to avoid implementation problems in practice, measurements were performed to verify the ability to read RFID tags in a laboratory environment, but with conditions close to real practice on the mobile device. [7],[9][5],[10] 
The experiments conducted at the Department of Industrial Engineering and informatics have been dealt with on the basis of practical requirements for RFID systems, where the correctness of reading is influenced by many factors. Since many businesses nowadays design and subsequently install information system based on RFID into practice, progressing by system try-mistake and pay little attention to loading intensity, focusing only on whether the system works and identifies the tag.

Measurements were performed in a laboratory that is not a perfectly sterile environment, it affected, that the results due to the reinforced concrete structure in the ceiling and floor area, as well as in the ceiling area, influenced by the electrical lighting and electrical installation. For the measurements, an area was graphically labeled. This is a $4.5 \times 5$-meter chessboard, evenly distributed every $0.5 \mathrm{~m}$ along its length and width. This division formed 90 squares $(0.5 \times 0.5 \mathrm{~m})$ and 110 interpolation points were formed by intersections (see Fig. 4). The tags were fastened using a telescopic stand and perpendicular to the intersections of the resulting surface.

The following devices and programs were used to measure:

- Lab computer Gaben TOUCH 24 ",

- MultiReader software (version 6.6.10),

- Speedway R420,

- Antenna Symbol AN480,

- laboratory stand Unomat,

- 3 tags (Siemens SIMATIC RF620T tag, UPM tag RAFLATAC DogBone 188_2, Confidex Ironside TM Global M4QT tag.

The following environmental factors were identified in the measurements:

- Temperature: $21^{\circ} \mathrm{C}$,

- Humidity: $53 \%$

- Pressure: $101 \mathrm{kPa}$.

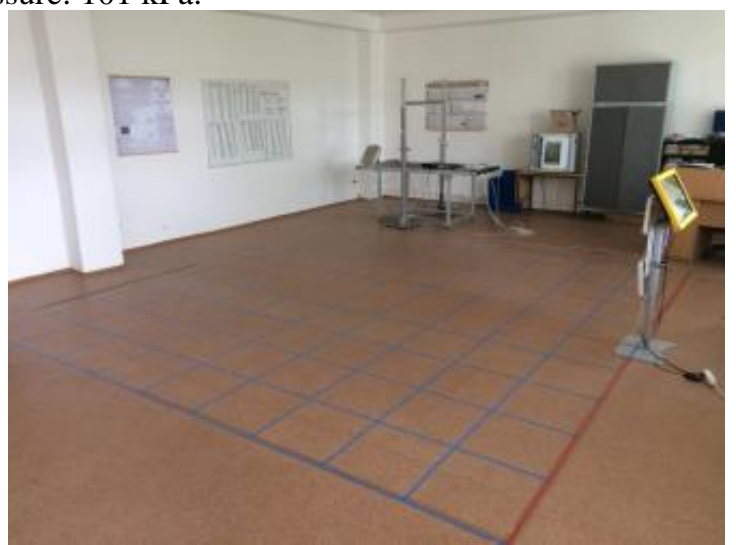

Fig. 4 Measuring area of laboratory and equipment Gaben TOUCH 24 with reader Speedway R420 


\section{Measurement of radiant characteristics}

The aim of the measurements was to verify the ability to read 3 types of passive RFID transponders (UHF tags) under laboratory conditions and to identify the ideal loading limit (95\% confidence limit). The tracked element is a qualitative parameter that expresses the number of readings of the RFID tag surveyed per count (TotCnt). RFID tags were tracked at different heights, ranging from 0-3 m in $0.5 \mathrm{~m}$ increments. Altogether, 2310 measurements were made on three RFID transponders, the results being to be used for the informatization process in practice. The technical parameters of the individual tracers are shown in Table 2.

Table 2. Overview of the technical parameters of the individual tags examined

\begin{tabular}{|c|c|c|c|}
\cline { 2 - 4 } \multicolumn{1}{c|}{} & \multicolumn{3}{c|}{ Tag type } \\
\cline { 2 - 4 } \multicolumn{1}{c|}{} & $\begin{array}{c}\text { Siemens } \\
\text { SIMATIC } \\
\text { RF620T }\end{array}$ & $\begin{array}{c}\text { UPM } \\
\text { RAFLATAC } \\
\text { DogBone 188_2 }\end{array}$ & $\begin{array}{c}\text { Confidex } \\
\text { Ironside } \\
\text { al M4QT }\end{array}$ \\
\hline Operating frequency & $860-960 \mathrm{MHz}$ & $860-960 \mathrm{MHz}$ & $860-960 \mathrm{MHz}$ \\
\hline Max read distance & $8 \mathrm{~m}$ & $6,1 \mathrm{~m}$ & $9 \mathrm{~m}$ \\
\hline Memory type & EEPROM & ------- & EEPROM \\
\hline EPC memory & $96 \mathrm{bits}$ & $96 \mathrm{bits}$ & $128 \mathrm{bits}$ \\
\hline Class & Class 1 & Class 1 & Class 1 \\
\hline User memory & $64 \mathrm{bits}$ & $32 \mathrm{bits}$ & $64 \mathrm{bits}$ \\
\hline capacity & IP67 & ------- & IP68 \\
\hline Safety standard & $127 \times 38 \times 6$ & $93 \times 23 \mathrm{~mm}$ & $\begin{array}{c}51,5 \times 47,5 \times 10 \\
\mathrm{~mm}\end{array}$ \\
\hline Dimensions & $18 \mathrm{~g}$ & $1 \mathrm{~g}$ & $22 \mathrm{~g}$ \\
\hline Weight & & & \\
\hline
\end{tabular}

After performing the measurements, it was found that, under the given conditions, the UPM RAFLATAC DogBone 188_2 transponder showed unsatisfactory results (unreliability, error, volatility of the load in the reserved area) throughout the measurement time. These inadequate results are related to its technical and design parameters.

Confidex The Ironside TM Global M4QT is a type of transponder that is specially made for unfavorable environments with interference elements. This is why the manufacturer has put on demand the increased requirements for its functionality and reliability compared to, for example, with the previous tag. The measurements have been confirmed by the manufacturer's listed properties (reduced defaults when loading a defined space) and therefore these types of trays are suitable for use in manufacturing systems where undesirable effects occur. 
The last tag that was subjected to the measurements was the Siemens SIMATIC RF620T tag. This tag has almost twice the size of the previous antenna. This fact manifested itself in an important feature, namely the ability to load. The larger antenna has ensured that the measured values have fluctuated very little. Also, another feature of the transponder has been promoted - an increase in the range of the tracking area, which is a relatively important indicator when using RFID technology. The measurements show that this type of transponder has achieved experimentally the best results, as evidenced by Fig. 5 and Fig. 6. The figures show the reliability, but also the loading stability at the height of $0 \mathrm{~m}$ (floor), $1.5 \mathrm{~m}$ and $3 \mathrm{~m}$ (ceiling). The red color indicates a $0 \%$ loading efficiency, a light green efficacy interval of $80-89.99 \%$, and a dark green $90 \%$ or more.
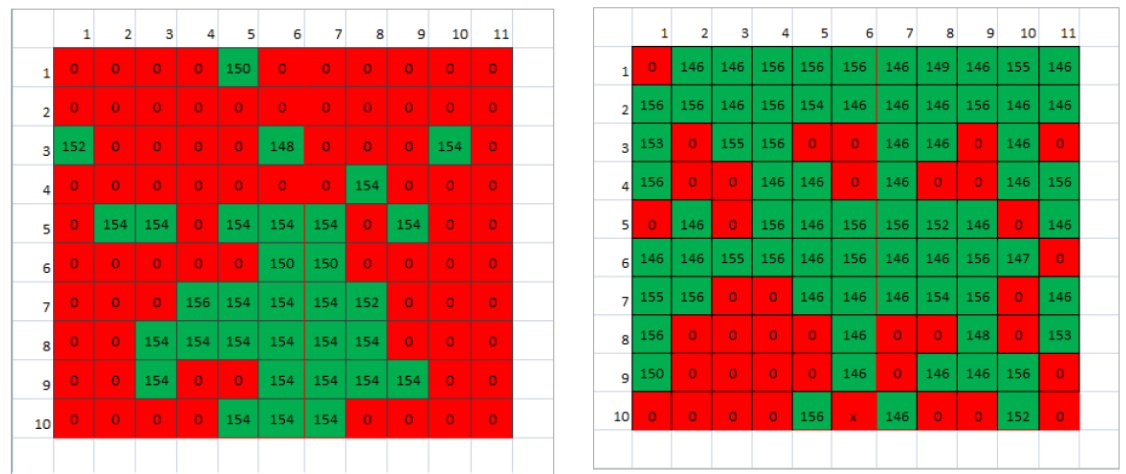

Fig. 5. Radiant characteristic of Siemens SIMATIC R620T at hight $0 \mathrm{~m}$ (left) a $3 \mathrm{~m}$ (right)

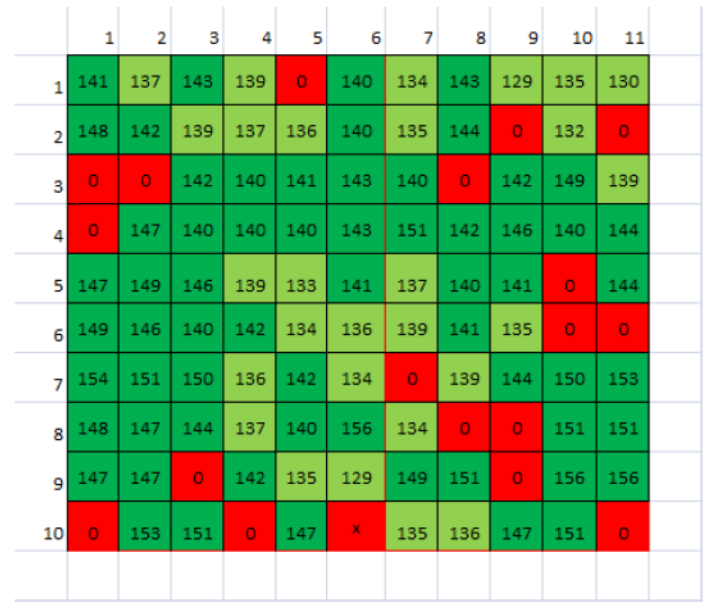

Fig. 6. Radiant characteristic of Siemens SIMATIC R620T at hight 1,5 m 


\section{Conclusions}

The article contains the outputs of experimental measurement that verified and also identified the quality of RFID tag transmission under laboratory conditions by simulating the real environment. The result contributes to raising the level of knowledge in the field of information flow monitoring for Industry 4.0 design needs. Since the measurements were performed under real conditions that were not modified (due to adverse effects - iron-concrete construction of the building and wiring), the results are comparable to what would be the loading of the individual tags in companies where they have similar undesirable effects. The results indicate that, in particular, the reading ability of the Confidex Ironside TM Global M4QT and the Siemens SIMATIC RF620T is such that it is better suited to environment where interference is taking place. By placing the trays at a height of $0.5 \mathrm{~m}$ from the ground to the edge of about $0.5 \mathrm{~m}$ from the ceiling, the loading efficiency of these pads is high. Of course, other factors, which have not been observed in the laboratory experiment, may be affected in practice, so it is advisable to implement the tags in a specific process (operation) and to investigate further their functionality and properties under the given operating conditions.

\section{Acknowledgement}

This work was supported by the Agency for Research and Development under the contract no. APVV-15-0602 and also by the Project of the Structural Funds of the EU, ITMS code: 26220220103.

\section{References}

[1] Sinay, J., Markulik, Š., Pačaiová, H.: Quality as a part of modern technology in the automotive industry / 2017. In: Smart City 360 2016. - Gent : EAI. pp. 1-8. (2017)

[2] Sinay, J., Pačaiová, H.: Sicherheit in der ,industrie 4.0-strategie“ - eine einführung / 2017. In: Sichere Arbeit. Vol. 1, pp. 40-46. (2017)

[3] Balog, M., Straka, M.: Logical Information Systems [Logické informačné systémy]. Bratislava: EPOS, pp. 208. (2005)

[4] Lehpamer, H.: RFID Design Principles. Norwood: Artech House, pp. 363. (2012)

[5] Hricová, R, Straka, M.: Opportunity of RFID using for intermodal transport in security of goods. In: Applied Mechanics and Materials. Vol. 718, pp. 162-167. (2015)

[6] Finkenzeller, K.: RFID HANDBUCH. Germany: HANSER, pp. 490. (2006)

[7] Rao K. V. S.; Nitkin P. V.; Lam S. F.: Antenna Design for UHF RFID tags: A Review and a Practical Application. IEEE Transactions on Antennas and Propagation. Vol. 53, no. 12, pp. 3870-3876. (2005) 
[8] Husár, J., Knapčíková, L., Balog, P.: RFID in railway transport in Slovakia [RFID v železničnej preprave na Slovensku]. Brno: Tribun EU, pp. 82. (2016)

[9] Kolarovszki, P. et al.: Laboratory testing of active and passive UHF RFID. In: Transport and telecommunication. Vol. 17, no. 2, pp. 144-154. (2016)

[10] Dupláková, D. et al.: Application of simulation tool for scheduling in engineering, In: Acta Simulation, Vol. 3, No. 1, pp. 5-10. (2017) 